\title{
Fracture analysis of the planet support used in a nuclear power plant
}

\author{
Shuai $Z u^{1}$, Xingang Guo ${ }^{2}$, Guangliang $X^{2}{ }^{2}$, Liangjia $C^{2}{ }^{2}$, Yinhui Che ${ }^{1}$ and Jianjun Guan ${ }^{1}$ \\ ${ }^{1}$ Suzhou Nuclear Power Research Institute, Equipment Management Department, 518000 Shenzhen, PR China \\ ${ }^{2}$ Hong YanHe Nuclear Power Plant, System Equipment Branch, 116000 DaLian, PR China
}

\begin{abstract}
In this paper, the fracture analysis of the planet support, which was made of aluminium alloy and used in an electric actuator, was investigated. The laboratory analysis was conducted to find out whether there are defects generated during manufacturing process. Besides, the finite element analysis was carried out to calculate the maximum tensile stress and compared it with the material strength. The mechanism of the fracture was found to be low-cycle fatigue.
\end{abstract}

\section{Introduction}

With a constant consumption of the fossil energy, nuclear energy is now playing an important role all over the world. During the safety management of the nuclear power plant, root cause analysis of the equipment failure is quite important to avoid the incident happening again. Electric actuators are widely used in nuclear power plants to drive valve, many of them are directly related to the nuclear safety.

Lots of analysis of the equipment failures in nuclear power plants was conducted. Failures of the different valves were investigated, such as slide valve, safety valve and forged valve $[1,2,3]$. But in this study, the fracture analysis of the planet support used in an electric actuator was conducted. The planet support was used to rotate the output shaft of the actuator and was made of aluminium alloy. The electric actuator used to work under an abnormal condition in which the motor starts frequently in a short time. SEM (scanning electron microscope) examination and metallography examinations were conducted to see micro-images of the material structure. Hardness and tensile strength tests were conducted to evaluate the mechanical properties of the aluminium alloy. Also, the stress calculation through finite element method was carried out to see the maximum tensile stress.

\section{Materials and methods}

\subsection{Materials}

The material of the planet support was aluminium alloy and the grade was EN AC-43100 (AlSi10Mg) without any artificial age-hardening treatment and solution treatment. According to the standard EN_1706 made by European Committee for Standardization, the element contents and mechanical properties, such as yield strength, tensile strength and fatigue strength of the AC-43100 had been clearly stipulated.

\subsection{Methods}

The sample of the aluminium alloy was taken out to do chemical composition analysis by infrared absorption method with inductive coupled high frequency plasma. The SEM images were observed at different scale of $100 \mathrm{um}$ and 500um using a scanning electron microscope of TESCAN VEGA TS5136XM. The metallographic examination was carried out using a metallographic microscope of ZEISSAXIOVERT 200.

Two different areas were chosen to do hardness test with the load of $10 \mathrm{~kg}$. A cylinder sample was taken out to do the tensile test.

\section{Results and discussion}

\subsection{Visual analysis}

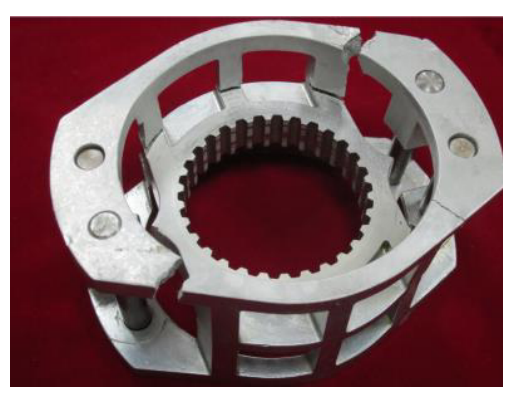

Figure 1. The fracture image of the planet support.

The planet support was broken into three parts. Through restoring these three parts, the two fractures were obvious and could not be recovered to the original position as shown in Fig. 1. This phenomenon was an 
indication that the two fractures were generated firstly. Besides, no obvious deformation was found on all fractures and all crack originations were found located at the corners in the structure.

\subsection{Chemical composition analysis}

The result of the chemical composition analysis was shown in Table 1. As we can see, all element contents were qualified to the standard EN_1706. No abnormality was found during the chemical composition analysis.

Table 1. Chemical composition analysis of the planet support.

\begin{tabular}{|c|c|c|}
\hline & Element contents (wt\%) & Standard EN_1706 \\
\hline $\mathrm{Si}$ & 9.77 & $9.0-11.0$ \\
\hline $\mathrm{Mg}$ & 0.22 & $0.20-0.45$ \\
\hline $\mathrm{Mn}$ & 0.12 & $\leq 0.45$ \\
\hline $\mathrm{Fe}$ & 0.38 & $\leq 0.55$ \\
\hline $\mathrm{Cu}$ & 0.011 & $\leq 0.10$ \\
\hline $\mathrm{Zn}$ & 0.014 & $\leq 0.10$ \\
\hline $\mathrm{Ti}$ & 0.11 & $\leq 0.15$ \\
\hline
\end{tabular}

\subsection{SEM images and Metallographic examination}
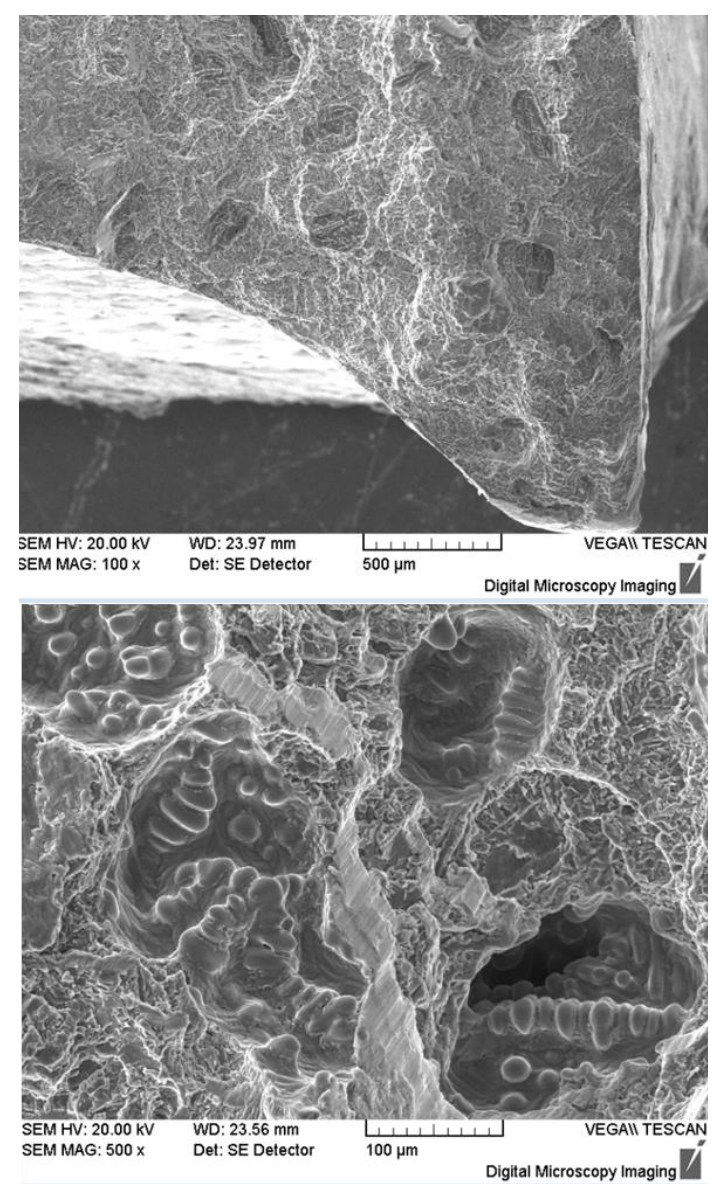

Figure 2. The SEM images of the fracture surface.

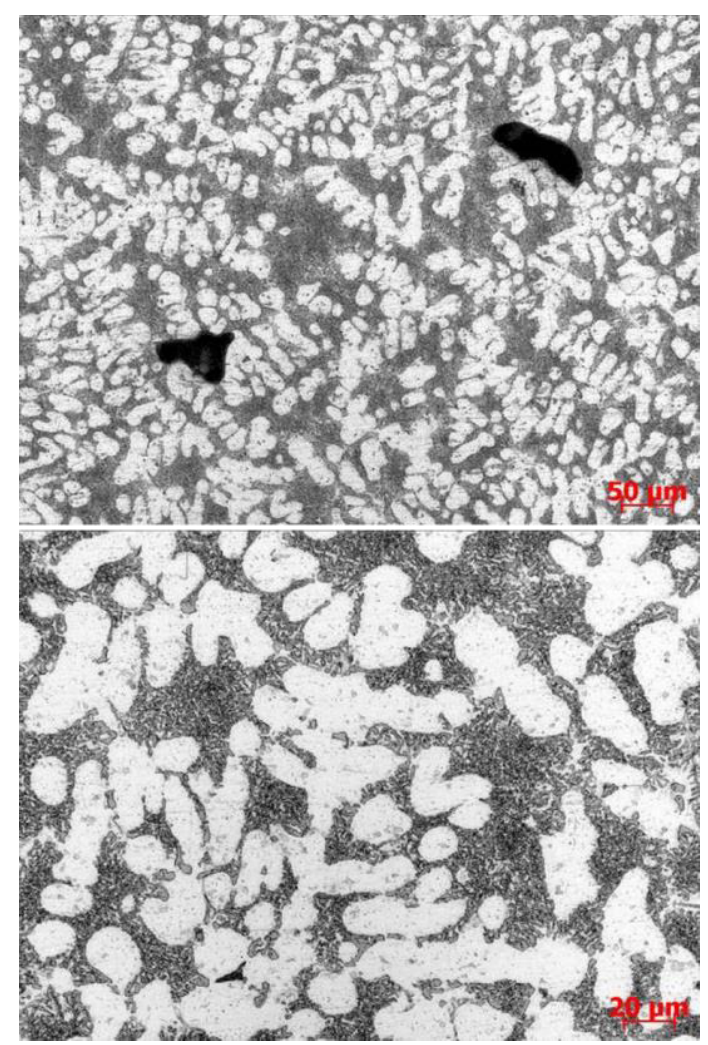

Figure 3. The metallographic images of the structure.

The micro-images of the fracture surface were shown in Fig. 2. The crack origination was observed under the scale of 500um, no plastic deformation was found. And through Energy Dispersive Spectrometer (EDS) measurement, no corrosion element was found near the crack origination.

Some holes were found in the structure as shown in the image of $100 \mathrm{um}$ scale, and the maximum diameter of the hole was $200 \mathrm{um}$. The holes were generated during manufacturing, and could affect the mechanical properties of the structure. The size of the holes will affect the mechanical properties as shown in the previous study [4].

The metallographic examination images were shown in Fig. 3. The primary crystal phase and eutectic phase could be observed through the picture. Also, some holes were found in metallographic images. No abnormal phenomenon was found through metallographic examination.

\subsection{Hardness test and tensile test result}

Table 2. Hardness test result of the planet support.

\begin{tabular}{|c|c|c|c|c|}
\hline No & \multicolumn{3}{|c|}{ Hardness value (HB) } & Average value \\
\hline 1 & 56.4 & 54.5 & 56.0 & 55.6 \\
\hline 2 & 63.4 & 63.7 & 62.5 & 63.2 \\
\hline \multicolumn{4}{|c|}{ HB $\geq 55$ (According to EN_1706) } \\
\hline
\end{tabular}


Table 3. Tensile test result of the planet support.

\begin{tabular}{|c|c|c|c|}
\hline & $\begin{array}{c}\text { Yield } \\
\text { strength } \\
\text { (MPa) }\end{array}$ & $\begin{array}{c}\text { Tensile } \\
\text { strength } \\
\text { (MPa) }\end{array}$ & Ductility(\%) \\
\hline Results & 136 & 191 & 3.5 \\
\hline EN_1706 & 90 & 180 & 2.5 \\
\hline
\end{tabular}

The result of hardness test was shown in Table 2. All values are qualified to the standard except the single value 54.5. But the average hardness values of these two different areas are qualified to the standard.

The tensile test result was shown in Table 3. As we can see, the mechanical properties such as yield strength, tensile strength and ductility value are all qualified to the standard.

\subsection{Finite element analysis}

A 3D mode of the planet support was created to show the stress distribution on the structure (as shown in Fig.4). The elastic-plastic mode was adopted in order to consider the non-linear character of the material.

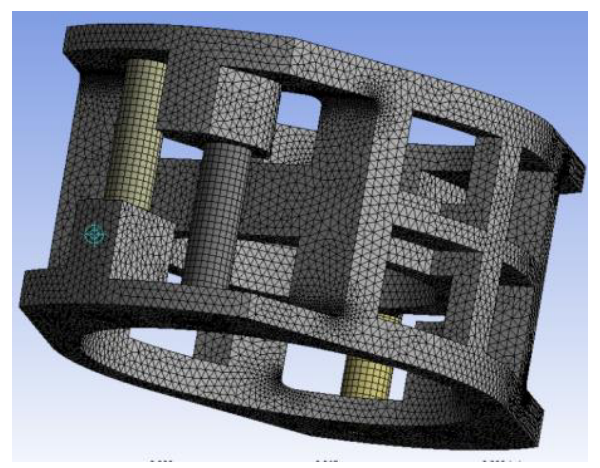

Figure 4. The 3D mode of the planet support.

A typical curve of out-put torque of the asynchronous motor was shown in Fig. 5. As we can see, the out-put torque is high when the motor starts. This start torque is nearly equal to the stall torque the motor. So the applied load on the planet support was nearly $840 \mathrm{~N} \cdot \mathrm{M}$ which corresponds to the maximum out-put torque of the electric actuator (stall torque).

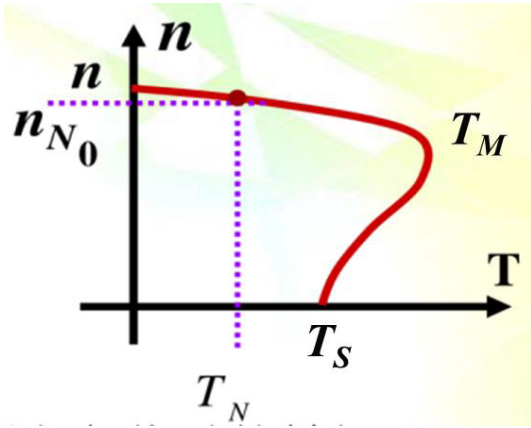

Figure 5. The out-put torque curve of the asynchronous motor.

The maximum tensile stress distribution was shown in Fig. 6. The location of the maximum tensile stress was corresponding to the crack origination in the two obvious fractures. Besides, the maximum tensile stress under the load $840 \mathrm{~N} \cdot \mathrm{M}$ was $132 \mathrm{MPa}$. According to the standard EN_1706, the yield strength and tensile strength were $90 \mathrm{MPa}$ and $180 \mathrm{MPa}$ respectively. The planet support should not be broken even if the motor was stalled. But, the planet support could also be broken if the motor started frequently in a short time, which corresponds to the fatigue fracture.

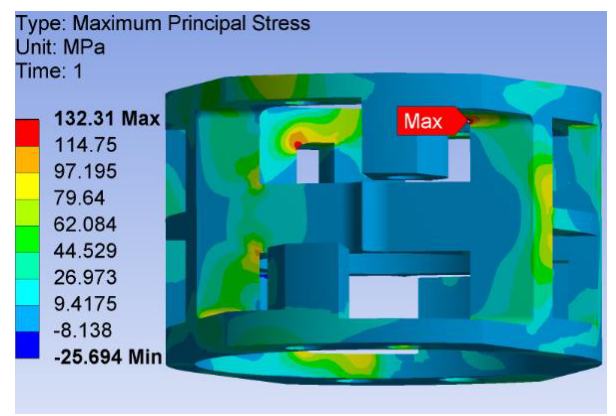

Figure 6. The tensile stress distribution.

\section{Discussion}

According to the laboratory analysis, no obvious manufacturing defects were found. Some holes were observed, while the mechanical properties were qualified to the standard through the tensile test. But, with the increase of the size of the holes, the fatigue life would be decreased [4]. It is also important to improve the casting process and enhance the quality control.

Through finite element analysis, the maximum tensile stress was less than the tensile strength of the material. But the planet support could also be broken due to the fatigue. According to the standard EN_1706, the fatigue strength of the AC- 43100 was $80-110 \mathrm{MPa}$ which corresponds to the fatigue life of $10^{6}$ times.

As we know, there is an inverse ratio relationship between the fatigue life and the stress or strain level. Fig. 7 shows a typical curve between the fatigue life and the strain level of the aluminium alloy AlSi7Mg with T6 treatment [5]. The maximum tensile stress of $132 \mathrm{MPa}$ which nearly corresponds to the strain $0.5 \%$, is excessively beyond the fatigue strength. If the cyclic strain is nearly $0.5 \%$ of the planet support, the fatigue life should be less than 1000 times as refer to Fig. 7.

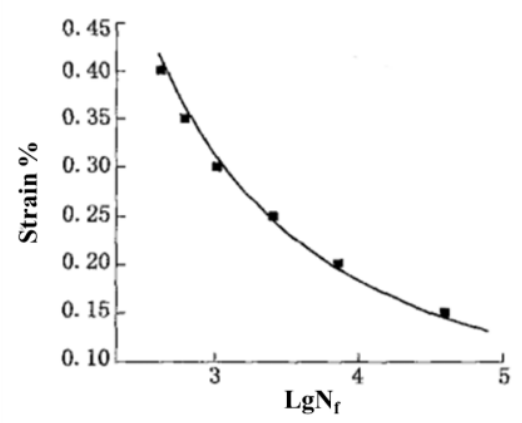

Figure 7. The relationship between the fatigue life and the strain level. 
The motor of the electric actuator used to start frequently due to the failure of the self-locker which was used to keep the rotation irreversible. The motor started every $0.2 \mathrm{~s}$ according to the current curve as shown in Fig. 8. The total time was nearly $144 \mathrm{~s}$ which corresponds to 720 cycles. The 720 cycles also corresponds to the lowcycle fatigue fracture as shown in Fig. 7.

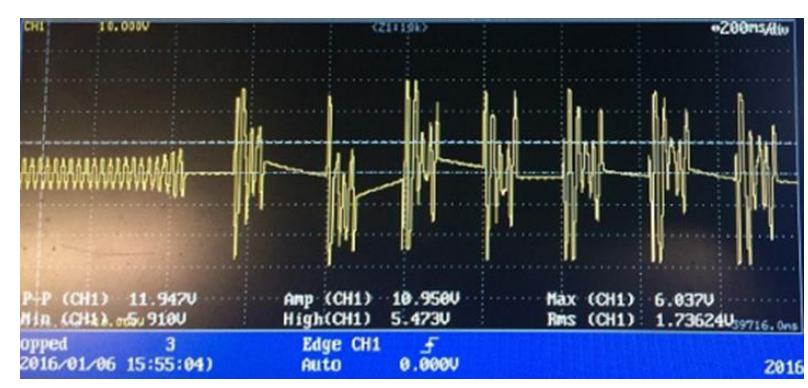

Figure 8. The current curve corresponds to the motor starts frequently.

\section{Conclusion}

Through chemical composition analysis, hardness test and tensile strength test, no abnormal phenomenon was found. Some holes were observed in SEM images and metallographic examination. The holes should be taken into consideration seriously during manufacturing in order to improve the mechanical properties.

The mechanism of the fracture of the planet support was proved to be low-cycle fatigue. Firstly, the abnormal working condition must be eliminated. On the other hand, as for design aspect, large radius is benefit for the structure due to the decrease of stress concentration.

Further studies should be focused on the effect on the mechanical strength caused by the defects generated during manufacturing process. Meanwhile, the manufacturing craft should also be improved to avoid the generation of such defects.

\section{References}

1. C.B Liu. S.L Jiang. Y.G Zheng. Experimental and computational failure analysis of a valve in anuclear power plant. Eng. Fail. Anal 22, 1 (2012)

2. B Panda, M Sujata, M Madan, S.K Bhaumik. Stress corrosion cracking in $316 \mathrm{~L}$ stainless steel bellows of a pressure safety valve. Eng. Fail. Anal 36, 379 (2014)

3. D Gallina. Finite element prediction of crack formation induced by quenching in a forged valve. Eng. Fail. Anal 18, 2250 (2011)

4. Xueyuan Xiang, Guoqiu He, Defeng Mo, Zhengfei $\mathrm{Hu}$, Bing Liu. Effect of microstructure on Al-Si casting alloy in fatigue lifetime progress. Shanghai Materials 31, 49 (2009)

5. Zhengyu Zhu, Guoqiu He, Chengshu Chen, Xia ngqun Ding, Xiaoshan Liu. Low Cycle Fatigue Behavior of ZL101 Aluminum Alloy. Special Casting \& Nonferrous Alloys 27, 256 (2007) 